\title{
ore O DIREITO FUNDAMENTAL À SAÚDE E (DES)RESPEITO DOS PLANOS DE SAÚDE
}

\section{Juliana Bedin Grando}

Doutoranda em Ciências Sociais na Universidade do Vale do Rio dos Sinos. Mestre em Direito com concentração em Direitos Humanos pela Universidade Regional do Noroeste do Rio Grande do Sul - Unijuí, com bolsa da Coordenação de Aperfeiçoamento do Pessoal de Nível Superior-Capes. Graduada em Direito pela Universidade Regional do Noroeste do Rio Grande do Sul - Unijuí. Advogada. Professora no curso de Direito URI - São Luiz Gonzaga. juliana.bedin@yahoo.com.br

\section{Maria Cristina Schneider Lucion}

Graduada em Direito pela Universidade Regional do Noroeste do Rio Grande do Sul - Unijuí. Especialista em Direito Empresarial e Advocacia Empresarial pela Universidade Anhanguera - Uniderp. Mestre em Direitos Humanos pela Universidade Regional do Noroeste do Estado do Rio Grande do Sul - Unijuí com bolsa Unijuí. mariacris. lucion@hotmail.com

\section{Resumo}

0 presente texto pretende analisar o direito à saúde no ordenamento jurídico brasileiro. 0 foco é, contudo, a verificação da efetividade do direito fundamental à saúde pelo Estado brasileiro e também a atuação subsidiária dos planos de saúde privados. Para tanto, analisa-se a incorporação dos direitos humanos reconhecidos internacionalmente no ordenamento jurídico brasileiro como direitos fundamentais. Busca refletir o papel do Estado na efetivação dos direitos fundamentais, analisando-se, para este fim, a possibilidade de utilização do sistema privado de saúde e como vem ocorrendo esta prestação. Objetiva-se, desse modo, identificar o papel desempenhado pelos planos de saúde na efetivação do direito fundamental à saúde. A metodologia utilizada na pesquisa é a hipotético-dedutiva, buscando-se uma conclusão. Apresenta algumas alternativas de controle do Estado para a fiscalização do sistema privado, tal como a resolução normativa ํo 309/2012, almejando-se demonstrar que a efetividade do direito deve ser o fim a ser buscado.

\section{Palavras-chave:}

Direitos fundamentais. Direito à saúde. Planos de saúde privados. 


\section{THE RIGHT TO HEALTH AND FUNDAMENTAL (DIS) RESPECT OF HEALTH INSURANCE}

\section{Abstract:}

This paper analyzes the right to health in the Brazilian legal system. The focus is, however, to verify the effectiveness of the fundamental right to health by the Brazilian government as well as subsidiary operations of private health plans. It analyzes the incorporation of internationally recognized human rights in the Brazilian legal system as fundamental rights. Seeks to reflect the state's role in the realization of fundamental rights, if analyzing for this purpose, the possibility of using the private health system and as it has this provision. The objective is to thereby ascertain the role played by health plans in the realization of the fundamental right to health. The methodology used in the research is the hypothetical-deductive, seeking a conclusion. It presents some State control alternatives for supervising the private system, as the rules Resolution No. 309/2012, aiming to demonstrate the effectiveness of the right should be the end being sought.

\section{Keywords:}

Fundamental rights. Right to health. Private health plans.

\section{Sumário}

1 Introdução. 2 0s direitos fundamentais no ordenamento jurídico brasileiro. 30 direito à saúde enquanto direito fundamental. 40 (des)respeito ao direito fundamental à saúde pelos planos privados. 5 Considerações finais. 6 . Referências. 


\section{INTRODUÇÃO}

Os direitos humanos são uma conquista histórica para os seres humanos, pois a partir do estabelecimento de preceitos básicos que devem ser observados assegura-se o maior bem humano: a vida. Nessa senda, falar em direitos humanos leva, necessariamente, a falar sobre a Declaraçáo Universal dos Direitos Humanos de 1948, pois configura-se em um dos documentos de maior prestígio, se náo o mais importante da história dos direitos humanos.

Assim, a partir dos preceitos e direitos básicos estampados na Declaraçáo, o sistema jurídico interno brasileiro incorpora estes direitos, elevando-os de patamar a partir da Constituição Federal de 1988. Tais direitos passam, então, a ser reconhecidos como direitos fundamentais e ganham um importante espaço na Carta Constitucional.

A problemática contemporânea emerge com a necessidade de dar efetividade a tais direitos. E, no presente texto, busca-se analisar como pode ocorrer a efetividade de um desses direitos fundamentais: o direito à saúde.

A sistemática comumente utilizada pelo Estado brasileiro dá-se por meio do sistema público de saúde, denominado Sistema Único de Saúde. Tendo-se em vista, no entanto, os diversos problemas existentes no sistema público - tais como a falta de médicos na quantidade necessária, falta de medicamentos - acrescidos da descrença da populaçáo brasileira em tal sistema, um sistema privado de saúde passa a ter atuação subsidiária: os planos privados de saúde.

Desse modo, o presente texto é dividido em três partes, nas quais se analisa em um primeiro momento a história e importância da construçáo dos direitos humanos; na sequência, verifica-se o direito à saúde como um direito humano e fundamental, resguardado pela Constituição Federal de 1988 e, por fim, observa-se a atuação dos planos privados de saúde pelo olhar da efetividade do direito à saúde.

\section{OS DIREITOS FUNDAMENTAIS NO ORDENAMENTO JURÍDICO BRASILEIRO}

A sociedade mundial passou por modificaçóes ao longo de sua História que levaram a diversas implicaçóes na vida da populaçáo, fato que pode ser percebido em muitos aspectos, tais como as formas compositivas da população, de poder, de 
controle social, entre tantas outras que fizeram com que a sociedade fosse adaptada à sistemática adotada à época em que se insere. Uma das mais significativas modificaçôes adentra-se na temática do reconhecimento dos direitos. A partir da teoria dos direitos naturais, dá-se início ao que se pode considerar a primeira forma de reconhecimento dos direitos como inerentes a todo ser humano. Continuamente na História, ao falar-se na luta pelo reconhecimento dos direitos humanos, o século 18 tem especial importância, quando se analisa os importantes documentos realizados nesse século, tais como a Declaração da Virgínia (1776) e a Declaração Francesa (1789).

Nesse sentido, acerca da importância da Declaração Francesa de Direitos do Homem e do Cidadão, Norberto Bobbio (2004, p. 39) expressa que

os testemunhos da época e os historiadores estáo de acordo em considerar que esse ato representou um daqueles momentos decisivos, pelo menos simbolicamente, que assinalam o fim de uma época e o início de outra, e, portanto, indicam uma virada na história do gênero humano.

Assim, a Declaração Francesa simboliza o início de uma nova acepção acerca dos direitos humanos, inaugurando-se uma nova era.

O século 19, por sua vez, traz o que Comparato (2010) trata como a primeira fase do processo de internacionalização dos direitos humanos, trazendo-se como documento de importância internacional a Convenção de Genebra de 1864, que visava em um primeiro momento à proteção às intempéries da guerra e que no ano de 1880 incidiu na criação da Comissão Internacional da Cruz Vermelha.

$\mathrm{Na}$ continuidade, o século 20 traz importantes movimentos que visam à proteção e incorporaçáo dos direitos humanos, como é o caso, por exemplo, da Carta Política Mexicana de 1917, a qual “[...] foi a primeira a atribuir aos direitos trabalhistas a qualidade de direitos fundamentais, juntamente com as liberdades individuais e os direitos políticos (artigos 50 e 123)" (COMPARATO, 2001, p. 184). Acerca da importância histórica para o cenário internacional, Comparato (2001, p. 184) acrescenta ainda que esta deve ser salientada “[...] pois na Europa a 
consciência de que os direitos humanos têm também uma dimensão social só veio a se afirmar após a grande-guerra de 1914-1918, que encerrou de fato 'o longo século XIX'[...]".

Desse modo, a Carta Mexicana representa este novo olhar que as Constituiçôes passam a trazer para os direitos humanos, incorporando ao cenário universal a ideia da dimensáo social desses direitos.

O período das grandes guerras (1914-1918 e 1939-1945), assim como o lapso inter-guerras, é de desrespeito aos direitos humanos. Nesse contexto, pode-se afirmar que somente com o encaminhamento para encerramento da Segunda Guerra Mundial, em 1945, é que se volta a incluir a importância dos documentos internacionais que assegurem os direitos humanos. É o que acontece com a Carta da ONU de 1945, que ocorre a partir da Declaração do Palácio de St. James (1941), Carta do Atlântico (1941), a Declaração das Naçóes Unidas (1942), que acabaram por levar para a Conferência sobre a Organização Internacional realizada em São Francisco (EUA) no ano de 1945 (ORGANIZAÇÃO..., 2014). Nesse sentido, a Carta da ONU foi o demonstrativo inicial do anseio pela paz mundial que os países integrantes desejavam e esperavam.

Passados três anos, em proclamação da Assembleia Geral das Nações Unidas, elabora-se um dos mais importantes documentos da temática dos direitos humanos, a Declaração Universal de Direitos Humanos de 1948. O período pós-Segunda Guerra Mundial traz consigo a necessidade de que se estabeleça patamares mínimos de direitos, universalmente reconhecidos, que garantam preceitos básicos para uma vida com dignidade e, assim, a Declaração insurge-se como esta possibilidade de reconhecimento e afirmaçáo dos direitos fundamentais.

E, neste escopo, "A idéia de direitos humanos ganhou demasiada importância ao longo da história, tendo em vista que seus pressupostos e princípios têm como finalidade a observância e proteçáo da dignidade da pessoa humana de maneira universal, ou seja, abrangendo todos os seres humanos" (BELLINHO, 2013, p. 4).

Ainda sobre a Declaração de 1948 é importante ressaltar que a 
Declaração Universal dos Direitos Humanos (DUDH) é um documento marco na história dos direitos humanos. Elaborada por representantes de diferentes origens jurídicas e culturais de todas as regióes do mundo, a Declaração foi proclamada pela Assembleia Geral das Naçóes Unidas em Paris, em 10 de Dezembro de 1948, através da Resolução 217 A (III) da Assembleia Geral como uma norma comum a ser alcançada por todos os povos e naçóes. Ela estabelece, pela primeira vez, a proteçấo universal dos direitos humanos (DECLARAÇÃO..., 2015).

Assim, a Declaração de 1948 consubstancia-se em plano mundial como um dos principais marcos protetivos, especialmente ao estabelecer o caráter universal e indivisível dos direitos. Em decorrência, com a realização da $2^{\text {a }}$ Conferência de Viena de 1993, dá-se início ao processo de internacionalização (PIOVESAN, 1999) e, ainda, a ampliação da rede protetiva dos direitos humanos (TRINDADE, 2000).

Ademais, "ao conjugar o valor da liberdade com o valor da igualdade, a Declaração demarca a concepção contemporânea de direitos humanos, pela qual esses direitos passam a ser concebidos como um unidade interdependente e indivisível [...]” (PIOVESAN, 1997, p. 159). Assim, após a Declaração inaugura-se, com este documento e a Conferência de Viena, a fase internacional dos direitos humanos, ampliando-se sua gama protetiva.

Já no plano interno, a Constituição Federal de 1988, conhecida como Constituição Cidadã, assegura a proteção dos direitos, demonstrando-se tal preocupação com a destinação de um título especialmente dedicado aos direitos fundamentais ${ }^{1}$.

Nessa senda, é importa relembrar:

Em que pese sejam ambos os termos ("direitos humanos" e "direitos fundamentais") comumente utilizados como sinônimos, a explicação corriqueira e, diga-se de passagem, procedente para a distinção é de que o termo "direitos fundamentais" se aplica para aqueles direitos de ser humano reconhecidos e positivados na esfera do direito constitucional positivo determinado pelo Estado, ao passo que a expressão "direitos humanos" guarda relação com os documentos de direito internacional, por referir-se àquelas posiçóes jurídicas que se reconhecem ao

1 Na Constituição de 1988 o título II é destinado à temática e tem por nomenclatura "Dos direitos e garantias fundamentais" e compreende os artigos $5^{\circ}$ a 17. 
ser humano como tal, independentemente de sua vinculação com determinada ordem constitucional, e que, portanto, aspiram à validade universal, para todos os povos e tempos, de tal sorte que revelam o inequívoco caráter supranacional (internacional) (SARLET, 1998, p. 31).

Assim, as nomenclaturas direitos humanos e direitos fundamentais diferenciam-se essencialmente pela amplitude do seu alcance. Para Sarlet (1998), os direitos humanos são aqueles previstos no plano internacional, enquanto os direitos fundamentais são os pertencentes ao direito positivo interno do país, como é o que ocorre na Constituição Federal de 1988, que incorpora do plano internacional os direitos humanos, utilizando-se nesta inserção a nomenclatura direitos fundamentais. $\mathrm{O}$ que importa ressaltar neste ponto é que independentemente do nome utilizado os titulares e destinatários são os seres humanos.

Ainda, quando se menciona em direitos fundamentais sociais, Sarlet (2001, p. 51) lembra que estes “[...] caracterizam-se, ainda hoje, por outorgarem ao indivíduo direitos a prestaçóes sociais estatais, como assistência social, saúde, educação, trabalho, etc., revelando uma transição das liberdades formais abstratas para as liberdades materiais concretas [...]".

Ademais, falar na conquista de direitos humanos e sociais

[...] supóe uma revoluçáo político-cultural que provoca mudanças no modo de pensar e agir conservador, ditatorial, não democrático, de concentração de riquezas intensamente presentes na sociedade brasileira. Estas mudanças geram também impactos na economia, no financiamento público. Sem essa mudança de entendimento nunca no Brasil poderiam ser praticados os direitos sociais e direitos humanos (SPOSATI, 2011, p. 21).

Desse modo, a revolução que a concepção de direitos humanos, sociais e fundamentais traz à tona para a sociedade demonstra esta conquista histórica social, de busca da democracia, de melhores condiçóes de vida, ou seja, de repúdio ao período ditatorial e de concentração de riquezas. Para que os direitos fundamentais sejam de fato efetivados, no entanto, é necessária essa modificação de pensamento e de agir da sociedade brasileira. E esta mudança trouxe consigo o anseio por se estabelecer as condiçóes dignas de existência, que serão alcançadas quando os direitos 
fundamentais forem efetivados. Pode-se afirmar aqui que a conquista dos direitos humanos e fundamentais trouxe uma nova concepção de sociedade e Estado, fazendo com que as transformaçóes daí decorrentes incidissem em diferentes áreas, tal como com a economia.

Ainda:

Os direitos fundamentais, são a um só tempo, direitos subjetivos e elementos fundamentais da ordem constitucional objetiva. Enquanto direitos subjetivos, os direitos fundamentais outorgam aos titulares a possibilidade de impor os seus interesses em face de órgãos obrigados. Na sua dimensão como elemento fundamental da ordem constitucional objetiva, os direitos fundamentais - tanto aqueles que não asseguram, primariamente, um direito subjetivo, quanto aqueloutros, concebidos como garantias individuais - formam a base do ordenamento jurídico de um Estado de Direito democrático (MENDES, 2004, p. 2).

Desse modo, os direitos fundamentais precisam ser compreendidos como a base do ordenamento jurídico, para a qual os cidadãos podem exigir seu respeito e efetividade. Outrossim, diante desses fatos, percebe-se a importância alcançada pelos direitos humanos e fundamentais. Para além disto, os direitos já amplamente reconhecidos revelam uma importante conquista para todos. A temática, entretanto, traz na atualidade um novo e necessário enfrentamento: Como dar efetividade aos direitos amplamente reconhecidos? Ainda, a questáo aqui posta remete à efetividade de especificamente um desses direitos fundamentais: o direito à saúde.

\section{DIREITO À SAÚDE ENQUANTO DIREITO FUNDAMENTAL}

Com a promulgação da Constituição de 1988, o Brasil volta a ser regido pelos preceitos de um Estado Democrático de Direito, ${ }^{2}$ incorporando ao ordenamento jurídico direitos constantes no plano internacional e que tem o condão de satisfazer os requisitos da cidadania de seu povo e ainda ofereçam a todos condiçóes de vida digna.

2 Com a reabertura do processo democrático em 1985, o Brasil passa a compor um novo período histórico de redemocratização, que ganha maior escopo com a Constituição Federal de 1988. 
Nessa senda, como já mencionado, muitos dos direitos reconhecidos, dentre os quais o direito à saúde, foram elevados ao patamar de direitos fundamentais, pois revelam-se de maior importância para o alcance da cidadania e constituem-se em peças basilares de efetivação do preceito da dignidade da pessoa humana.

Da mesma forma,

[...] há como afirmar, sem medo de errar, que a despeito da existência de pontos passíveis de crítica e ajustes, os direitos fundamentais estão vivenciando o seu melhor momento na história do constitucionalismo pátrio, ao menos no que diz com seu reconhecimento pela ordem jurídica positiva interna e pelo instrumentário que se colocou à disposição dos operadores do Direito, inclusive no que concerne às possibilidades de efetivação sem precedentes no ordenamento nacional [...] (SARLET, 1998, p. 72).

Partindo dessa premissa de que os direitos fundamentais constituem-se em uma das maiores conquistas dos cidadãos brasileiros, tem-se como um desses direitos assim elencados o direito à saúde, que vem estampado no artigo 60, ${ }^{3}$ artigo que compóe o título "Dos direitos e garantias fundamentais", ou seja, o direito à saúde é reconhecido no ordenamento jurídico como um dos direitos sociais e, portanto, deve ser estendido a todos os brasileiros.

Ademais, a fim de dar maior alcance a este direito, consta ainda na Constituição a "Seção II" denominada "Da saúde" em que se encontram os parâmetros para dar efetividade ao direito estampado no artigo $6^{\circ}$. Ressalte-se, por exemplo, o disposto no artigo 196, que garante que a saúde é um direito universal e cabe ao Estado garanti-la por meio de políticas públicas sociais e econômicas que visem à redução do risco de doenças, com o acesso igualitário às açôes e serviços para a sua promoção, proteção e recuperação. Desta forma, diante dessas disposiçóes, outras legislaçóes relacionadas com a temática da saúde foram editadas. $\mathrm{O}$ disposto na

3 Art. 6. São direitos sociais a educaçáo, a saúde, a alimentação, o trabalho, a moradia, o lazer, a segurança, a previdência social, a proteção à maternidade e à infância, a assistência aos desamparados, na forma dessa Constituição. 
Constituição Federal, no entanto, já constitui a obrigação do Estado brasileiro em prestar esse direito a todos de maneira que efetivamente garanta o acesso igualitário a tal direito.

Embora amplamente positivado, no entanto, o direito à saúde muitas vezes não é totalmente efetivado pelo Estado. O que se tem percebido no cenário atual é a quase completa ineficácia do Estado em garantir que o direito à saúde, de maneira universal, reconhecido como essencial para a formaçáo da cidadania, seja de fato oferecido a todos. Igualmente, quando se fala nas políticas públicas relativas ao tema, que são uma das principais formas de se alcançar tal direito, estas são quase inexistentes e/ou praticamente ineficazes, acarretando, por conseguinte, diversos problemas sociais.

Assim, uma alternativa que se tem mostrado eficaz é a participação da sociedade civil na realização de políticas públicas que efetivem o direito à saúde, bem como que exerçam o seu papel fiscalizador perante o Estado, no entanto, se não ocorrer a prestação do direito à saúde pelo Estado, e sendo este uma garantia fundamental para a efetivação da cidadania, há a possibilidade de se exigir o seu cumprimento pelo ente estatal.

Por ser uma prestação positiva, uma das formas encontradas para ampliar o acesso e garantir o direito à saúde é a sua judicialização. Esta, por sua vez, tem-se revelado uma das únicas formas de se efetivar o direito, o que mostra cada vez mais a ineficácia estatal na prestação dos direitos.

Desse modo, a questáo da saúde constitui-se um tema cada vez mais controverso e que necessita mais atenção. $\mathrm{O}$ direito à saúde é um direito amplamente reconhecido no ordenamento jurídico, mas que necessita cada vez mais a intervenção judicial para ser obtido. A cidadania do brasileiro está sendo posta em questáo quando não se garante a este as condiçóes sanitárias básicas para que possa viver com o mínimo existencial, que é dever do Estado, que ao chamar para si a responsabilidade de garantir a todos os cidadãos brasileiros as condiçóes básicas de existência como tal, deve cercar-se de medidas que atendam a essas necessidades.

Necessário ressaltar que o direito à saúde é um direito universal do indivíduo e não somente do cidadão na sua concepção mais clássica, uma vez que qualquer sujeito dentro do território de um Estado Democrático de Direito necessita ser 
beneficiado pelo atendimento a sua saúde, uma vez que a concepção de Estado de Direito, ${ }^{4}$ ou Estado de lei, fundamenta-se nos direitos humanos, e estes garantem o direito à vida, a sua preservação, como também, especificamente, o direito à saúde.

Frise-se aqui que para o Estado Democrático de Direito "[...] estão presentes as conquistas democráticas, as garantias jurídico-legais e a preocupação social" (STRECK; MORAIS, 2010, p. 97), de modo que, ao se assegurar a efetividade do direito à saúde, estar-se-á assegurando os preceitos do próprio Estado.

Nesse contexto, quando se menciona a infligência do direito à saúde se está conjuntamente falando na desvalorização do Estado como Democrático de Direito e como Estado social, pois deixa de alcançar as condiçóes mínimas para a efetivação da cidadania, esta inter-relacionada intrinsecamente com a existência do próprio Estado. Assim, ao falar que o Estado deixa de fornecer condiçôes aos seus cidadãos para que alcancem um direito fundamental, como o direito à saúde, estar-se-á negando os propósitos de qualquer Estado democrático e violando-se direitos internacionalmente reconhecidos como direitos humanos. Desse modo, cabe ao Estado prestar, sob quaisquer condiçôes, os mínimos essenciais de vida a todo cidadão, garantindo-se assim que o princípio da dignidade da pessoa humana seja alcançado por todos e, nesse aspecto, a prestação do direito à saúde insere-se como um desses mínimos que deve ser garantido à universalidade dos indivíduos, como forma de existência digna.

\section{0 (DES)RESPEITO AO DIREITO FUNDAMENTAL À SAÚDE PELOS PLANOS PRIVADOS}

Embora reconhecido na Constituição Federal como um direito fundamental, e como tal, deve ser prestado pelo Estado, a realidade social brasileira revela que a preocupação com a saúde e a atual situação da saúde pública, fazem com que a população procure outros meios de proteção. É o que ocorre com a busca pelos planos privados de saúde.

4 "Estado de direito é um Estado ou uma forma de organização político-estatal cuja actividade é determinada e limitada pelo direito" (CANOTILHO, 1999, p. 11, grifo do autor). 
Assim, é preciso ter em mente que "a atual configuração da ordem social constitucional permite que no Estado brasileiro coexistam, de forma independente, uma rede pública e uma privada” (FIGUEIREDO, 2012, p. 6). É de grande relevância, também, considerar o papel subsidiário dos entes privados, em especial dos planos de saúde, no que respeita à garantia de eficácia do direito à saúde por meio da obrigação de assistência médica.

Os planos privados de assistência à saúde e o sistema público podem e devem conviver, pois

a atuação subsidiária das entidades privadas na efetivação de políticas de saúde pode ser assim sugerida como caminho que retoma a idéia de solidariedade [...]. Trata-se de uma alternativa a ser desenvolvida com seriedade, por abrir novas possiblidades à consecução exitosa do direito fundamental à saúde (FIGUEIREDO, 2007, p. 101).

Tal fato demonstra que as entidades privadas de planos de saúde constituíram-se especialmente porque o poder público mostra-se falho em algumas oportunidades, fazendo com que emergisse em grande parte da populaçáo a necessidade de assegurar sua própria segurança médica, independente de atuação estatal. Desse modo, por meio dos planos de saúde, os contratantes passam, via de regra, a usufruir de um serviço médico previamente contratado e garantido de maneira privada, sem deixarem de ser titulares do direito à saúde pública.

Destarte, ante o parcial fracasso do sistema público na área da saúde, cada vez mais a populaçáo busca atendimento e segurança médica nos meios privados, que são destinados apenas àqueles que têm condiçóes financeiras de arcar com seus custos. Assim, a crescente contratação de planos de saúde ocorre, não raras vezes, em razão de uma utópica (e mercadológica) expectativa de segurança e atendimento médico integral pelos meios privados.

Dessa forma, por tutelar de maneira privada a saúde, impende ao Estado o dever de regular e fiscalizar a atuação dos planos de saúde, eis que

pela natureza de seu objeto, que responde a necessidades vitais de preservação e promoção da vida e da saúde dos consumidores, assumem relevância social e jurídica diretamente afeta ao direito fundamental à saúde, consagrado na 
Constituição Federal. Isso fundamenta tanto a intervenção do Estado no condicionamento da liberdade contratual das partes, quanto indica a orientação e o sentido desta intervenção (MIRAGEM, 2012, p. 357).

Neste contexto, importa ter em mente que "o sistema privado de saúde possui caráter complementar ao público, de forma que ninguém pode ser compelido a contratar nem filiar-se ao sistema autônomo de saúde, sob pena de flagrante inconstitucionalidade" (SCHWARTZ apud FIGUEIREDO, 2007, p. 99). Ou seja, a adesão ao sistema privado de saúde é facultativa ao usuário, de modo que, ainda que venha a ser consumidor de um plano de saúde, o cidadão permanece sendo beneficiário da assistência pública fornecida pelo Estado.

Ademais, cumpre salientar que, em relação à saúde privada, a Constituição Federal determina, no já mencionado artigo 197, que é dever do Estado regulamentar, fiscalizar e controlar os serviços de saúde, inclusive os prestados por pessoas jurídicas de direito privado. Dessa forma, também ganha relevância o princípio da equidade, o qual busca equilibrar a relação mantida entre o consumidor-segurado e operadora do plano de saúde, levando em conta o histórico da relação jurídica estabelecida entre as partes.

Outrossim, o contexto da assistência médica privada ganha maior relevância quando se coloca em voga o grande número de usuários do sistema. Segundo o último levantamento realizado pelo Conselho Federal de Medicina em 2010, cerca de 46,6 milhóes de pessoas, o equivalente a $24 \%$ da população brasileira, eram usuárias de planos de assistência médica no Brasil, e esse número vem crescendo de maneira acentuada. Segundo a Agência Nacional de Saúde Suplementar (ANS), os planos privados de assistência à saúde são classificados na regulamentação desta Agência, com base na fórmula de contratação (artigo 20 ${ }^{\circ}$, Resoluçáo Normativa - RN/ANS no 195/2009), em individuais/familiares, coletivos por adesão e coletivos empresariais.

O primeiro obstáculo à efetivaçáo do direito à saúde por meio dos planos privados é a postura adotada pela Agência Nacional de Saúde Suplementar, que costuma ser mais rígida e regular o percentual de reajustes e coberturas oferecidas tão somente em planos individuais ou familiares. Ou seja, o órgão estatal é firme e regula os reajustes das mensalidades de planos individuais, que são a minoria, deixando de regular os reajustes dos planos coletivos empresariais e por adesão. 
Com efeito, os planos de saúde coletivos por adesão são os típicos planos "para livre adesão de beneficiários, pessoas naturais, com ou sem grupo familiar" (artigo 30, $\mathrm{RN} \mathrm{n}^{\circ}$ 195/2009). Assim, um grupo de pessoas ligadas a um sindicato ou associação unem-se e contratam um plano de saúde por seu intermédio, que não participa ou contribui com a mensalidade, apenas intermediando a contratação do plano com a operadora.

Já os planos coletivos empresariais caracterizam-se pela existência de um terceiro elemento que se coloca entre o usuário do serviço e a operadora de plano de saúde, fornecedora dos serviços. Esse "terceiro elemento" é o empregador desse usuário, que geralmente participa das negociaçóes de reajustes.

Nesse contexto, veja-se que, segundo informaçóes da Agência Nacional de Saúde Suplementar (ANS), a contratação de planos coletivos (empresariais e por adesão) corresponde a 78,5\% do total de planos de saúde comercializados. Em 2001, quando o número começou a ser monitorado, apenas 43\% dos usuários estavam em planos de saúde coletivos.

Isso posto, todo esse cenário de manutenção e promoção do direito à saúde pelo meio privado conduz ao inevitável questionamento acerca de seu funcionamento e respeito às normas constitucionais, especialmente porque o sistema privado exclui todo e qualquer usuário que não tenha condiçóes financeiras de arcar com seus custos. Assim, impende uma sucinta análise acerca dos reajustes aplicados pelos planos de saúde como fator de efetivação do direito à saúde, conforme se faz a seguir.

Dada a diferenciação entre contratos de planos de saúde coletivos e familiares, é imprescindível destacar que, como estratégia de captação de consumidores, as operadoras costumam ofertar planos coletivos alardeando as mensalidades iniciais com valores bastante inferiores aos das mensalidades dos planos individuais. $\mathrm{O}$ que não é divulgado é que o contratante de um plano coletivo (empresarial ou por adesão) fica sujeito a reajustes não regulados pela Agência Nacional de Saúde Suplementar, o que tende a tornar as mensalidades mais caras com o passar do tempo. Ou seja, grande parte dos usuários é atraída por menores preços num primeiro momento, mas não tem previsibilidade do preço futuro, sendo surpreendida com aumentos bem maiores do que a ANS define para os planos individuais, caso utilizem a cobertura oferecida. 
A utilização desta prática por parte das operadoras afronta diretamente qualquer nível de razoabilidade, eis que por meio de aumentos abusivos as operadoras acabam impossibilitando a continuidade do usuário no plano. Tais aumentos ocorrem anualmente em razão de cláusulas contratuais abusivas e que colocam o usuário em posição desfavorável diante da operadora.

Assim, a cláusula que estabelece o reajuste maior do que os índices de mercado é abusiva, pois não possibilita ao usuário o conhecimento total daquilo que irá ocorrer durante o contrato, atribuindo todo o poder de condução do contrato à operadora. O artigo 51 do Código de Defesa do Consumidor, por sua vez, prevê serem cláusulas abusivas e, portanto, totalmente nulas, as que permitam ao fornecedor, direta ou indiretamente, variação do preço de maneira unilateral.

É notável que no caso de reajustes exorbitantes não está especificado o índice utilizado para aumento das mensalidades, dificultando a observância deste por parte do usuário, o que configura cláusula abusiva. Os aumentos ficam estabelecidos pela operadora de plano de saúde de forma unilateral, sem qualquer alegaçáo consistente e sem a demonstração de quais índices são utilizados, configurando-se, assim, a violação ao direito à saúde do segurado.

É neste ponto que o Estado falha no que diz respeito à assistência privada à saúde, pois permite que os contratos de planos de saúde sejam regulados exclusivamente pela Agência Nacional de Saúde Suplementar, a qual se exime de regular contratos coletivos, causando sérios riscos ao direito à saúde dos usuários. As deficiências dessa Agência são perceptíveis especialmente quando está em pauta a discussão acerca dos aumentos abusivos, sendo possível, segundo a doutrina, concluir dois fenômenos: um de excesso de confiança na competência regulatória das agências e outro de edição de regulamentação frágil (MIRAGEM, 2012).

Nesse sentido, os aumentos abusivos das mensalidades ocasionam o desequilíbrio econômico dos contratos de plano de saúde, especialmente quando os reajustes levam em consideração fatores como risco e sinistralidade, solidariedade e mutualidade e tempo. A solidariedade, por sua vez, é o fator ligado à idade dos consumidores, uma vez que 
o grupo de segurados ou de consumidores presentes no plano se une, em mutualidade, pois expostos aos mesmos perigos, às mesmas probabilidades de danos à saúde, unem-se solidamente para organizar uma espécie de fundo gerado pelo fornecedor que organiza uma cadeia de prestadores de saúde ou reembolsa despesas de saúde e gere verbas. Para garantir que poderão manter-se no sistema, apenas de aposentados e mais doentes, os consumidores ligam-se ao sistema enquanto ainda jovens e por muito tempo contribuem para o sistema, devendo os cálculos do fornecedor assegurarem que os mais novos poderão sustentar no sistema, aqueles com maior sinistralidade (MARQUES, 2014, p. 418).

De fato, a utilização desses fatores faz com que o plano de saúde seja "lucrativo" para a operadora enquanto os usuários não o utilizam; quando os usuários envelhecem e passam a utilizar com mais frequência o plano, contudo, as mensalidades são reajustadas supostamente para "reequilibrar o contrato" por meio de aumentos exorbitantes.

Essa prática abusiva é repetidamente vedada pelos tribunais brasileiros, eis que ocorre a nítida violaçáo do direito à saúde dos usuários por meio de mensalidades que são impossíveis de pagamento, ocasionando a retirada forçada do plano, como é o caso do Tribunal de Justiça do Estado de São Paulo (2012) que reconhece que

Numa visão estritamente econômica do contrato, ao se onerar a carteira, impedindo reajuste na exata proporção do aumento do risco do idoso, estará o serviço se tornando mais caro para os novos consumidores. Há, porém, uma distorção em tal ponto de vista, pois o novo consumidor, ao aderir a contrato relacionado, não almeja somente o maior benefício ao custo imediato, mas sobretudo que a cobertura negocial permaneça ao longo do tempo e quando mais dela precisar. Razoável, até mesmo para os novos consumidores, que o custo adicional que consumidores mais idosos seja entre todos distribuído, garantindo que ao seu tempo, que chegará antes do que se espera, a situação atuarial se inverterá. É por isso que Ronaldo Porto Macedo Jr. defende que a solidariedade nos contratos relacionais, cuja essência é o vínculo recíproco de cooperação, a consciência da interdependência de cada um dos seus participantes, numa relaçáo de apoio direcionada ao mesmo fim (BRASIL, 1998, p. 178-179). 
Desse modo, dadas as consideraçóes expostas, evidencia-se que os reajustes abusivos aplicados pelas operadoras em contratos coletivos são inexigíveis. Isto porque, por ser a saúde um direito fundamental e em razão da peculiaridade da relação jurídica estabelecida entre operadora e usuário, e o fato de o Estado se omitir e não regular os reajustes aplicados nestes contratos, não autoriza o reajuste unilateral $\mathrm{e}$ infundado da mensalidade do contrato.

Ainda é necessário ressaltar que a Resolução Normativa no 309/2012 da Agência Nacional de Saúde Suplementar, que determina que as operadoras formem agrupamentos com todos seus contratos coletivos com menos de 30 beneficiários para o cálculo do percentual de reajuste, foi criada com o notável escopo de conferir não somente alguma garantia aos usuários, mas também para afastar os abusos que muitas vezes são praticados nesses tipos de contrato. Tal norma, portanto, não justifica o reajuste sem a devida comprovação da elevaçáo do custo.

Por todo o exposto, considerada a importância do direito à saúde, a luta histórica para seu reconhecimento, a atuação estatal, bem como os planos privados de saúde deve atentar-se para a efetividade de tal direito. Ao se reconhecer o direito à saúde como um direito fundamental, de cunho universal, não se pode aceitar a atuação privada sem qualquer interferência do poder público. A fiscalização deve ser aumentada para que o direito à saúde seja prestado, sem se colocar de lado a dignidade da pessoa e o maior direito de todo ser humano: o direito à vida. Assim, a atuação dos planos privados deve ser fiscalizada e condizer com as diretrizes de efetividade dos direitos fundamentais.

\section{CONSIDERAÇÕES FINAIS}

A história humana é cercada pela busca do reconhecimento de direitos que assegurem as condiçôes mínimas de existência. A modernidade trouxe consigo guerras mundiais que dizimaram quase que por completo os direitos humanos anteriormente conquistados. Nessa senda, o período pós-guerras traz consigo a necessidade de se repensar os ditames humanos e novamente se estabelecer um padrão mínimo de direitos a todos os seres humanos. 
Nesse contexto, a Declaração Universal de Direitos Humanos de 1948 representa esse importante passo da humanidade na busca de direitos, pois além de estabelecer um extenso rol de direitos, assegura a sua universalidade. Nesse sentido, o processo de internalização destes direitos consagra-se no cenário brasileiro através dos direitos fundamentais, estampados na Constituição Federal de 1988, sendo um dos direitos reconhecidos como fundamentais o direito à saúde.

O Estado brasileiro, no entanto, não tem conseguido dar efetividade a este direito fundamental da forma esperada quando da contratação do plano, fazendo com que a população recorra a meios alternativos de consecução deste direito. A alternativa encontrada dá-se mediante os planos privados de saúde.

A problemática insere-se no desrespeito que a iniciativa privada responsável por estes planos de saúde vem causando para a população brasileira ao não observar as garantias legais, o direito à saúde e o direito à vida. A situação agrava-se quando se trata de planos de saúde coletivos, que correspondem à grande maioria das contrataçôes e que sofrem reajustes abusivos, enquanto o Estado é omisso em sua regulação.

Diante de tais fatos, conclui-se com a presente pesquisa que os planos privados de saúde não estão cumprindo o que se espera, bem como estão desrespeitando o direito à saúde, tendo uma visão apenas mercadológica da saúde. Da mesma forma, o Estado, além de não conseguir alcançar efetividade ao direito fundamental, também não tem conseguido atuar em seu papel fiscalizador, demostrando um total desrespeito à vida humana.

\section{REFERÊNCIAS}

AMARAL JUNIOR, Alberto do; PERRONE-MOISÉS, Cláudia (Org.). O cinquentenário da Declaração Universal dos Direitos do Homem. Sáo Paulo: Edusp, 1999.

BELLINHO, Lilith Abrantes. Uma evolução histórica dos direitos humanos. 2013. Disponível em: <http://www.unibrasil.com.br/arquivos/direito/20092/lilith-abrantes-bellinho.pdf>. Acesso em: 28 jul. 2014.

BOBBIO, Norberto. A era dos direitos. Rio de Janeiro: Elsevier, 2004. Disponível em: $<$ http://direitoufma2010.files.wordpress.com/2010/05/norberto-bobbio-a-era-dos-direitos. pdf>. Acesso em: 25 jul. 2014. 
BRASIL. Contratos relacionais e defesa do consumidor. São Paulo: Max Limonad, 1998. p. 178-179

CANOTILHO, José Joaquim Gomes. Estado de direito. Lisboa: Fundação Mário Soares, 1999.

COMPARATO, Fábio Konder. A afirmação histórica dos direitos humanos. 2. ed. São Paulo: Saraiva, 2001.

DECLARAÇÃO UNIVERSAL DOS DIREITOS HUMANOS. DUDH. ONU. Disponível em: <http://www.dudh.org.br/>. Acesso em: 26 jan. 2015.

FIGUEIREDO, Leonardo Vizeu. Curso de direito de saúde suplementar (manual jurídico de planos e seguros de saúde). 2. ed. Rio de Janeiro: Forense, 2012.

FIGUEIREDO, Mariana Filchtiner. Direito fundamental à saúde: parâmetros para sua eficácia e efetividade. Porto Alegre: Livraria do Advogado, 2007.

MARQUES, Cláudia Lima. Contratos no Código de Defesa do Consumidor. 6. ed. São Paulo: Revista dos Tribunais, 2014.

MENDES, Gilmar Ferreira. Os direitos fundamentais e seus múltiplos significados na ordem constitucional. Anuario iberoamericano de justicia constitucional, n. 8, p. 131-142, 2004. Disponível em: <https://scholar.google.com.br/scholar?start=60\&q=direitos+fundamenta is\&hl=pt-BR\&as_sdt=0,5>.

MIRAGEM, Bruno. Curso de direito do consumidor. São Paulo: Editora Revista dos Tribunais, 2012.

ORGANIZAÇÃO DAS NAÇÓES UNIDAS. ONU. Disponível em: <http://www.dudh. org.br/>. Acesso em: 26 jan. 2015.

. A carta das Naçôes Unidas. 2014. Disponível em: <http://nacoesunidas.org/carta/>. Acesso em: 20 ago. 2015.

PIOVESAN, Flávia. Direitos humanos e o direito constitucional internacional. 2. ed. São Paulo: Max Limonad, 1997.

. Direitos humanos globais, justiça internacional e o Brasil. AMARAL JUNIOR, Alberto do; PERRONE-MOISÉS, Cláudia (Org.). O Cinquentenário da Declaração Universal dos Direitos do Homem. São Paulo: Edusp, 1999.

SARLET, Ingo. A eficácia dos direitos fundamentais. Porto Alegre: Livraria do Advogado, 1998. - A eficácia dos direitos fundamentais. 2. ed. rev. atual. Porto Alegre: Livraria do Advogado, 2001. p. 51. 
SPOSATI, Aldaíza. A menina Loas: um processo de construção da Assistência Social. 6. ed. São Paulo: Cortez, 2011.

SCHWARTZ, Germano A.; GLOECKNER, Ricardo Jacobsen. A tutela antecipada no direito à saúde: aplicabilidade da teoria sistêmica (de acordo com a Lei 10.444/02). Porto Alegre: Sergio Antonio Fabris Editor, 2003.

STRECK, Lenio Luiz; MORAIS, José Luis Bolzan de. Ciência politica e teoria do estado. 7. ed. Porto Alegre: Livraria do Advogado, 2010.

TRINDADE, Antônio Augusto Cançado. A proteção internacional dos direitos humanos e o Brasil. 2. ed. Brasília: Universidade de Brasília, 2000.

Recebido em: 31\8\2015

Aceito em: $8 \backslash 6 \backslash 2016$ 